\title{
A inclusão escolar do ponto de vista dos professores: o processo de constituição de um discurso*
}

\author{
Hildete Pereira dos Anjos \\ Emmanuele Pereira de Andrade \\ Mirian Rosa Pereira \\ Universidade Federal do Pará, Faculdade de Educação de Marabá
}

\section{Introdução}

Este artigo apresenta os resultados da pesquisa intitulada “A experiência de inclusão dos alunos com necessidades especiais nas escolas públicas de Marabá: primeiras avaliações”, que deu continuidade à tese de doutorado O espelho em cacos (Anjos, 2006), que analisou os discursos presentes e em enfrentamento nas falas dos professores responsáveis pelo atendimento de alunos com necessidades educacionais especiais, numa experiência de inclusão escolar. Feita a análise dos discursos oficial (no que tange à formação de professores), acadêmico (sobre as nuances do conceito de inclusão em textos de 1998, 2001 e 2004) e escolar (especificamente os discursos dos professores de atendimento especializado de alunos cegos, com baixa visão e surdos), tornou-se importante agregar a essa análise novos elementos, visando a um esboço multidimensional da realidade estudada e, portanto, melhores condições de nela intervir.

* Pesquisa realizada com apoio do Programa de Auxílio à Instalação do Professor Recém-Doutor (PARD), da Universidade Federal do Pará (UFPA), no ano de 2007.
A pesquisa propôs-se a, dentro da produção de um quadro avaliativo da experiência de inclusão escolar no município de Marabá, ${ }^{1}$ analisar as falas dos professores coletadas em entrevistas não-estruturadas. Em tal análise, atentou-se para a descrição que eles fazem de si mesmos e de sua atuação, o lugar do outro, os sentimentos em relação ao processo de inclusão, as compreensões de deficiência, normalidade e inclusão, assim como as expectativas com relação à aprendizagem e ao desenvolvimento dos alunos. Tais agrupamentos de sentido foram analisados internamente e em inter-relação, buscando evidenciar as estratégias e os modos de operar do discurso (Verón, 2004), os quais evidenciam, dissimulam ou ocultam temáticas e questões (Orlandi, 2005) envolvidas no debate.

\footnotetext{
${ }^{1}$ O município de Marabá situa-se no sudeste do estado do
} Pará, dentro do espaço geográfico conhecido como Amazônia Oriental, a 530km de Belém, capital do estado. No município, o processo inclusivo teve início em 2001, quando as salas especiais foram extintas e seus alunos foram distribuídos nas salas de aula regulares, dando início à estruturação de um atendimento educacional especializado (Marabá, 2001). 


\section{Inclusão: um conceito em elaboração}

O conceito de inclusão foi elaborado em um movimento histórico que tem suas origens nas lutas das pessoas com deficiência por acesso à educação. Tem, portanto, nas suas bases, a história da educação especial. Tal história geralmente é descrita como um processo evolutivo que atravessa um período de segregação, passa por esforços integrativos e deságua no movimento inclusivista. Cada um desses momentos pode ser caracterizado tendo como referência três aspectos: o lugar do indivíduo e da sociedade, o foco adotado pelo campo científico e as práticas decorrentes. Ainda que não se compartilhe de uma visão linear desse processo, é importante descrever brevemente cada um desses momentos.

Nas práticas segregacionistas iniciais, que buscavam educar o deficiente entre seus iguais, afastando-os do restante da sociedade, a deficiência era tida como própria do indivíduo e a ciência empenhava-se em caracterizar e categorizar os distúrbios a partir de um modelo médico da deficiência, amparado na categorização, na prevenção e na busca de cura. "A segregação”, diz Mendes (2006, p. 387-388), “era baseada na crença de que eles [crianças e jovens com deficiência] seriam mais bem atendidos em suas necessidades educacionais se ensinados em ambientes separados”.

As críticas a tais concepções e práticas evoluíram para uma visão integracionista: no campo científico, a ênfase deslocou-se dos fatores orgânicos ou individuais para os fatores sociais ou ambientais, ocorrendo um processo de transição do modelo médico para o modelo social da deficiência (Marchesi \& Martin, 1999, p. 11); os esforços pedagógicos concentraram-se em adequar a pessoa com deficiência, aproximando-a ao máximo dos padrões da escola comum. No campo prático, abriram-se espaços, na escola regular, para a presença de pessoas com deficiência, geralmente agrupadas em classes especiais. Mesmo quando participando da sala regular, no entanto, o que se pretende destacar é que, numa visão integracionista, a presença de tais alunos não modifica a lógica de funcionamento da escola.
É justamente a crítica a essa concepção que está na base da lógica inclusiva: a atuação conjunta de pessoas que vivem diferentemente o acesso ao conhecimento deveria contagiar o coletivo, abrindo novas experiências curriculares, flexibilizando a grade de disciplinas e a estrutura de séries; enfim, criando novas lógicas no interior da escola e nas relações educativas como um todo. A educação especial deixaria de existir como campo distinto, transformando-se em atendimento educacional especializado, que funcionaria como suporte ao trabalho da sala de aula e às relações gerais da escola. Em vez de serem envidados esforços para fornecer à pessoa condições de adaptarse à escola, procurar-se-ia construir uma escola para atender às pessoas concretas que fazem parte dela. No campo da ciência, tratar-se-ia de perceber os processos de construção social da deficiência e fazer a crítica da concepção do corpo belo e produtivo como referência para o humano (Diniz, 2007), assim enfatizar o modelo social em seus aspectos antropológicos.

A difusão das ideias inclusivas adotadas no Brasil como linha política e a decorrente decisão de matricular na escola regular os alunos com deficiência trouxeram à luz o fato de que concepções e práticas segregacionistas, integracionistas e inclusivistas convivem e se enfrentam no cotidiano das escolas. Pode-se atribuir tal situação ao fato de que as propostas de inclusão foram trazidas de outros países, com histórias diferenciadas de atendimento à deficiência, muitas vezes ignorando o trajeto real da educação especial no Brasil. No entanto, a par disso, é preciso considerar que o fato de ser elaborada uma proposição tida como melhor ou mais abrangente não implica necessariamente o desaparecimento das proposições que ela pretende superar: essa é a noção de ideia recessiva, a qual, ainda que subjugada, sobrevive no interior da práxis (Anjos, 2006). Dessa forma, tais enfrentamentos se refletem na constituição histórica do processo de inclusão e, consequentemente, de seus sentidos, que passam por oscilações, como evidenciado em Anjos (2006, p. 305-306):

Como as teorias educacionais não estão descoladas dos modos de pensar a sociedade, a ideia de inclusão se expande e se con- 
trai: em alguns discursos, representa uma mudança localizada que necessariamente se articula com as mudanças necessárias para a superação do modo de vida capitalista; em outros, uma mudança no interior da educação que mostra a possibilidade de se criar consenso dentro desse mesmo modo de vida, melhorando as relações gerais no mesmo processo em que são reduzidas as hostilidades e preconceitos entre pessoas e grupos; em outro ainda, uma pseudomudança que serve para que tudo continue como está (o movimento necessário para que nada mude).

Assim, quando se busca nas falas dos professores os processos de produção de sentidos acerca da experiência da inclusão, deve-se levar em conta que tal processo incorpora o fazer/pensar concreto dos professores em sua rede de relações; aponta, portanto, elementos muito mais significativos para uma análise do processo inclusivo do que simplesmente comparar o que deveria ser a inclusão (em modelos de outros países ou em textos de referência) com o que se está fazendo de fato nas escolas. Isso porque, em tais modelos de pesquisa, a práxis indefectivelmente perde: ela nunca consegue alcançar aquilo que é pensado como teoria.

\section{Concepções e lugares presentes na falas dos professores}

A construção de um dispositivo de análise e interpretação para estudar discursos de professores já tinha sido realizada em Anjos (2006). Nele, considera-se o pedagógico como um gênero de discurso, entendendose gênero como um dos "tipos relativamente estáveis de enunciados” elaborados nos campos de utilização da língua (Bakhtin, 2003, p. 261). Para efeito deste trabalho, esse gênero sofreu um recorte: foi analisado apenas o discurso que perpassa as falas do professor de sala comum, considerando que as falas do professor de atendimento educacional especializado (AEE) já tinham sido analisadas em Anjos (2006) e as falas de pais, alunos e pessoal de gestão deverão ser analisadas na continuidade da pesquisa. ${ }^{2}$ Entende-se o

${ }^{2}$ O Grupo de Estudos e Pesquisas do Núcleo de Educação Especial (GEP/NEES) da Faculdade de Educação de Marabá/ discurso como construção histórica (Vygotsky, 1989, 1996, 1998, 2000), no qual se enfrentam interesses, apresentando-se como um fazer, uma prática discursiva (Pêcheux, 2006; Foucault, 2006). Nosso interesse foi buscar entender os modos de funcionamento do discurso (Orlandi, 2005), articulando as temáticas que emergem nas conversações com os modos discursivos de operar (Verón, 2004; Anjos, 2006). Os agrupamentos de sentido descritos a seguir expressam essa busca de articulação, sendo expressão do diálogo entre nossa compreensão e as relações de sentido presentes nos textos. Tais relações articulam os elementos que de fato se apresentam nas falas (marcas textuais que expressam temáticas e modos de operar). As temáticas aqui analisadas não são necessariamente aquelas propostas por nós, mas aquelas que emergem nas falas (Anjos, 2006), seguindo, desviando, contrapondo-se, enfim, dialogando com nossa fala.

Dentro dessa linha, o dispositivo de análise e interpretação utilizado permitiu elaborar três grandes agrupamentos de sentido nas falas dos professores, que foram denominados: a) concepções de base, no qual aparece o entendimento que o professor expressa de deficiência, normalidade e inclusão; b) o lugar de si, no qual o falante descreve a si mesmo e suas relações no processo de inclusão, dando ênfase à postura profissional, aos sentimentos, às aprendizagens, ao processo de formação; c) o lugar do outro, no qual o falante elege interlocutores privilegiados e os descreve, destacando o governo, o sistema escolar, o atendimento especializado, pais e os alunos, assim como as expectativas de aprendizagem e o desenvolvimento desses últimos.

Antes de passar a relatar a forma de interpretação dos dados, faz-se necessário esclarecer a terminologia assumida, dada a diversidade de termos e os enfrenta-

Universidade Federal do Pará (UFPA) executa o projeto “Educação inclusiva em municípios do Pará - o caso de Marabá”, complementando a avaliação do processo inclusivo no município, como parte do programa de pesquisa "Olhar, escutar e vivenciar a educação inclusiva em municípios do Pará”, da Rede de Pesquisa em Educação Inclusiva na Amazônia Paraense, financiado pelo Conselho Nacional de Desenvolvimento Científico e Tecnológico (CNPq). 
mentos entre os autores sobre o "nomear correto" no campo da inclusão (Marchesi \& Martin, 1996; Cartolano, 1998; Omote, 2004; Anjos, 2006, entre outros). Designar-se-á, neste artigo, "pessoa com deficiência", assumindo sua condição de pessoa inteira e sua deficiência construída socialmente, mas a ela remetida (Diniz, 2007); quando a limitação for específica, utilizar-se-á "pessoa surda” (Skliar, 2001), “pessoa cega” etc. Quando se tratar de uma especificidade educacional, far-se-á referência a essa necessidade educacional especial, entendendo-a não como uma característica da pessoa, mas necessidade do coletivo que a deseja educada, que entende como fundamental (para todos) sua inclusão em relações sociais e educativas menos discriminatórias. Assim, a expressão "pessoa com necessidades educacionais especiais”, que deu título ao projeto original de pesquisa e é utilizada em Anjos (2006), deixa aqui de fazer sentido, entendendo-se que toda pessoa tem necessidades educacionais especiais. Neste artigo a ênfase é dada às necessidades educacionais geradas pelas situações de deficiência.

\section{As concepções de base}

As concepções que emergem nas falas dos professores aparecem em três noções inter-relacionadas: as concepções de normalidade, de deficiência e de inclusão. A concepção de normalidade pode ser organizada em dois grupos. O primeiro recusa o conceito, questionando a ideia de normalidade; desse ponto de vista, não existem normais, ou cada um só é normal até certo ponto. O segundo assume a existência de uma normalidade. Para alguns professores, normalidade tem relação com a aceitação pelo outro, fazer coisas comuns, participar, interagir, brincar. "Eles já participam de todo o dia-a-dia do comportamento das brincadeiras de tudo... ela passa a ser uma criança normal e aceita pelos colegas” (Ent. A, p. 4, ls. 192-194³).

${ }^{3}$ As citações extraídas das transcrições das sessões de entrevistas são indicadas pela letra de referência da sessão (A, B, C,ou D), seguida da indicação da(s) páginas(s) e da(s) linha(s). Por exemplo: Ent. A, p. 2, ls. 12-115.
A entrada na normalidade pode significar também a superação dos déficits ou a responsabilização do indivíduo por eles:

\section{[...] então eu falo exclusivamente desses alunos... porque os outros que a gente trabalha ela até tirou do programa dela lá... porque eles não são mais considerados pessoas espe- ciais... alguns que eram anteriormente com ela... que já são considerados pessoas normais... se tiver algum déficit é falta de vontade deles mesmo... certo? (Ent. B, p. 4, ls. 195-199)}

Assim como a de normalidade, a concepção de deficiência aparece nas falas dos professores de duas maneiras principais: como característica humana geral ou como especificidade de alguns. Como especificidade, é relacionada com apatia, lentidão, isolamento, como problema (para o professor, porque transparece nas falas que é ele quem tem de equacionar a situação). Mesmo quando o conceito de deficiência é descrito como característica humana geral, distinguem-se certos alunos como tendo uma deficiência "mais aguda": "Todos nós temos uma deficiência... a deficiência dela é mais aguda” (Ent. A, p. 3, l. 152). Quando relacionadas a dificuldades de aprendizagem, elas aparecem como geradas pelo pouco esforço dos alunos. Isso agrupa alunos "deficientes" e "preguiçosos", e mais uma vez a superação das limitações não catalogadas como deficiência é entendida como dependendo do esforço e do querer do aluno:

Porque deficiente é o deficiente, não são só aqueles alunos
que são realmente que tem um problema, não... Tem uns
alunos que são normais mas que eu também os considero...
alguns os considero como deficientes também... porque são
alunos que num... têm dificuldades de aprendizagem... têm
dificuldade de... de compreensão de texto... tem alunos com
dificuldades, é... é assim que num querem, sabe? Que num
querem... que num têm um esforço... então esses alunos
também que a gente considera como normais... acaba sendo
também uma... uma deficiência... (Ent. H, p. 3, ls. 116-124)

Nessa fala, percebe-se que a noção de deficiência vincula-se ao indivíduo; não é tomada como produção 
da cultura. Embora sejam culturais as caracterizações, assim como o processo de catalogação ora considerando o indivíduo deficiente, ora isentando-o disso, a interpretação é de que a deficiência tem relação com a falta de disposição pessoal para aprender.

A concepção de inclusão também aparece em duas formas básicas: como processo e como produto. Ao ser definida como processo, inclusão implica tentativas, erros e acertos de todas as pessoas envolvidas; ao ser definida como produto acabado, cabe às pessoas aceitá-la ou não. Faz-se essa distinção porque, conforme o falante compreenda inclusão como processo ou produto acabado, como fruto da ação humana (Anjos, 2006, p. 307-308) ou como coisa dada, estará pressuposta ou não a possibilidade de interferir nela. Dentro do primeiro termo dessa oposição, emerge outra, na qual a inclusão aparece como um processo que ocorre com os outros ou como um processo que envolve o falante. No primeiro agrupamento, incluir é algo externo ao falante, ele próprio entendendo-se como "incluso" e sentindo-se responsável pela tarefa de incluir outras pessoas. No segundo, ele se entende como parte do processo, como na seguinte fala:

\footnotetext{
A chamada inclusão seria... como o pessoal fala, é trazer um aluno deficiente pro nosso meio, mas ele já vive no nosso meio... Então essa inclusão seria mais você: não é trazer ele pro nosso meio e sim você ir pro meio dele... porque você que passa a: conviver a situação dele, a ver de que forma que ele vive, a ver de que forma assim que... qual é o tipo de vida dele... o que que ele faz pra poder chegar aqui... ele pega ônibus, ele tem uma necessidade especial né... às vezes perda de visão... um ônibus passa não pára... às vezes passa pelo local de parada não respeita... Então não é ele que tem que se incluir a você e sim você tem se incluir a ele... Eu vejo esse lado [...]. A partir do momento em que você respeitar ele não devido a ele ter uma perda de visão... mas se você respeitar ele como ser humano... você consegue ter essa inclusão... (Ent. J, p. 3-4, ls. 144-153 e 155-157)
}

Quando a ideia de inclusão é descrita como um produto, algo acabado, surge mais como uma questão de compreensão, algo no campo das idealizações. Duas falas mostram isso claramente: "e até hoje inclusão realmente não é bem vivenciada nem aceita...” (Ent. E, p. 2, ls. 98-99); “infelizmente, a maioria ainda não entendeu realmente o que que é inclusão... infelizmente não entenderam...” (Ent. E, p. 3, ls. 122-123). As práticas não-inclusivas assentam-se numa não-aceitação da inclusão, aqui entendidas como uma falha do entendimento. Nesse modo de operar do discurso, os saberes relativos à inclusão são dados como já constituídos (Anjos, 2006, p. 303), devendo ser entendidos e aplicados pelos profissionais da escola; não aparecem, portanto, como projeto a ser construído.

Olhando por um outro ângulo, pode ser estabelecida outra oposição, na qual a inclusão é referenciada no seu oposto, a exclusão, ou explicada em si mesma. Essa última definição pode ser encontrada quando o falante diz que "a inclusão não existe" ou "a maioria ainda não entendeu realmente o que é inclusão” (Ent. E, p. 3, ls. 122-123); isso pressupõe a existência de uma inclusão a priori, definida fora das contradições do humano. Já a contraposição inclusão/exclusão admite tais contradições, como nas falas a seguir:

Eu queria explicar realmente o que é inclusão... Assim, eu vejo que há necessidade da gente trazer/tirar aquelas pessoas daquela marginalização e dar uma condição melhor de vida, sabe? Através da educação... Ensinando a fazer alguma coisa, que melhore a quali/que possa produzir... gerar rendas... (Ent. H, p. 4-5, ls. 197-201)

[...] e essa história agora vem... isso já é antigo de que o pessoal tão falando “inclusão... inclusão”, mas numa escola pública dizendo que ia ter... Isso pra mim num, num é inclusão..., inclusão deveria ser... juntar os meninos tudinho... “num sabe ler, num sabe escrever? Umbora segurar eles, umbora tentar ver o que a gente consegue fazer”. Juntar com todos que não têm dificuldade... e tenta ajudar o máximo que a gente pode... não adianta [...]. Vai passar o menino sem saber nada... (Ent. C, p. 1, ls. 16-19 e 25-29)

Relacionando o modo como apareceram essas três concepções, é possível afirmar a existência de 
uma naturalização como modo de operar discursivo da temática da deficiência ("todos somos deficientes") e da temática da normalidade (“não existem normais”). Tal naturalização tanto pode contribuir para uma aproximação das diferenças quanto para reduzir as especificidades a uma "diferença" homogeneizada, não sendo muito distinta, em seus efeitos de sentido, daquela naturalização criada pelos processos segregativos, que atribuía ao indivíduo a responsabilidade pela deficiência.

Entendendo-se a diferença como característica humana geral, as lutas por participação social mais efetiva das pessoas com deficiência - por inclusão, portanto - e as denúncias das situações de discriminação e preconceito podem perder força. Em contrapartida, historicizando-se a noção de diferença e situando cada especificidade nesse processo (os preconceitos contra as pessoas surdas são diferentes dos preconceitos contra a pessoa com deficiência mental, assim como são diferentes as limitações sociais construídas para cada um deles, para só citar dois casos), tais lutas e denúncias podem articular-se e fortalecer-se mutuamente. Operar com o conceito de inclusão como processo (no qual o falante se inclui) faz parte dessa segunda compreensão (Mendes, 2006). Entendê-la como produto, coisa pronta e acabada, que deve existir porque a legislação obriga ou porque é de “bom tom”, por seu lado, possibilita explicá-la em si mesma e não por contraposição a processos excludentes (Libâneo, 2005), naturalizando-a.

\section{O lugar onde o falante se coloca nos processos inclusivos}

A segunda grande linha de interpretação agrupa os sentidos em torno do lugar que o falante elege para si mesmo no discurso, organizados em torno das seguintes temáticas: sentimentos dos professores com relação à inclusão, qualidades que o professor atribui a si mesmo, aprendizagem do professor no processo de inclusão e postura profissional.

Os sentimentos dos professores com relação ao processo de inclusão foram organizados em três gru- pos de sentidos que emergiram das falas: sentimentos descritos como positivos ou negativos e sentimentos de crise e de transição. Não são, necessariamente, excludentes entre si; aparecem constantemente sentimentos contraditórios na fala de um mesmo professor.

Os sentimentos positivos que mais se destacam nas falas são o amor e a satisfação por trabalhar com alunos com deficiência:

\begin{abstract}
Olha, amor... o amor e o carinho muito grande por ela (a turma com a qual a entrevistada atua)... Eu vou me aposentar... não sei o que vou fazer, que eu vou me aposentar (risos). Eu tenho que me acostumar... que não é gostar... é vício (risos), é vício, eu sou... eu sou viciada em escola... eu moro aqui (na escola), menina. (Ent. A, p. 5-6, ls. 206 e 301-304)
\end{abstract}

[Ver] que ele aprende e faz sozinho... aquilo é gratificante, a gente se sente... muito bem. Porque ele, você sabe que ele tem uma dificuldade maior, e então ele... por ele conseguir, a gente se sente muito bem por ter conseguido, ensinado, e por ele ter conseguido alcançar o objetivo dele. (Ent. F, p. 3, ls. 147-151)

Relacionado a esses sentimentos está o gosto por aprender com o processo de inclusão, no qual os professores entendem que puderam modificar-se e tiveram crescimento profissional.

\footnotetext{
Ah, isso aí, agora eu vou te dizer... é uma coisa muito boa, assim, é, eu mesmo, eu tenho crescido muito profissionalmente com eles... principalmente quando... eu fico assim feliz quando vejo... tenho notícia da minha primeira aluna DV... que é a T... Se tenho notícia de que ela fez vestibular e passou e tá cursando faculdade... isso pra mim foi algo gratificante, eu saber que eu contribuí... mesmo aprendendo mais com ela do que eu... Então isso é gratificante demais... (Ent. I, p. 4, ls. 180-187)
}

Como sentimentos negativos, foram incluídos os estereótipos que organizam a relação com o aluno que apresenta deficiência: alunos com deficiência mental como apáticos, que estão sempre "fora do ar" etc. Sentir que o outro está “fora do ar” está relacionado às 
dificuldades de comunicação, que são relacionais, ou seja, estão tanto no professor quanto no aluno, mas só são atribuídas ao primeiro. Nas falas, aparecem constantemente as dificuldades encontradas pelo professor no trabalho que podem ser relacionadas ao sentimento de impotência do professor diante das próprias limitações e das limitações sociais; frustrações sofridas por ele, que geram um sentimento de não-realização profissional.

Porque no nosso caso aqui eu não tinha trabalhado com educação especial, então a gente chega assim, já é difícil numa sala, a sala dela é a quinta série, que tem cinquenta alunos... então já é difícil trabalhar com todos esse alunos, ainda mais quando se tem um aluno que é da... tá incluído, que é de educação especial, tem que dar uma atenção maior pra ele, muita vezes você não tem esse tempo de ir lá na carteira dele explicar, porque é muito tumultuante cinquenta alunos, então deveria diminuir, né, o número, pra ser uma inclusão... (Ent. F, p. 2, ls. 87-94)

Eu me sinto... impotente às vezes... porque mesmo que eu queira ajudar é difícil, porque... eu não posso ficar exclusivo de um menino às vezes... porque toda vez eu falo com a [nome da responsável pelo atendimento especializado] pra mim ficar dando atenção a um às vezes só... é complicado... (Ent. C, p. 3, ls. 120-123)

Chama a atenção, nas duas falas, a aflição por não conseguir dar atendimento individualizado, entendendo-o como pré-condição para o atendimento aos alunos com deficiência. $\mathrm{O}$ professor, de fato, não pode dar atenção a um aluno só, mas isso não aparece como um problema quando se descreve o seu trabalho como um todo, apenas em relação aos alunos com deficiência. Entretanto, ele também não poderia atender a cinquenta alunos de quinta série (hoje sexto ano), independente da presença de pessoas com deficiência na turma, mas essa quantidade aparece naturalizada, como se tivesse que ser assim.

Certos sentimentos foram analisados como de transição, mesmo que possam ser interpretados como positivos ou negativos em dadas circunstâncias. Na fala a seguir, por exemplo, o sentimento de frustração é associado ao desejo de contribuir mais: “[...] realizada? Não, não... eu ainda me sinto muito frustrada, ainda... ainda sinto que eu posso ou poderia contribuir muito mais...” (Ent. D, p. 4, ls. 162-163).

São sentimentos que evidenciam a crise vivida pelos professores, com potencial para alavancar experiências produtivas. Entre esses sentimentos, destacam-se: o choque sentido pelos professores no início do trabalho com alunos deficientes, que faz com que ele perceba um vazio na sua formação, a falta de um treinamento e o fato de que esses novos sujeitos que estão na sala de aula exigem novas capacidades e novos modos de pensar; a certeza de que estão improvisando, que pode levar a descobrir novos fazeres e saberes, não necessariamente subordinados ao "fazer correto"; as dificuldades encontradas pelo professor, as quais podem ajudar a acordar de um fazer pedagógico que, por ter-se tornado automático, se tornou "fácil"; a necessidade que o professor sente de ser instigado, incentivado diante das dificuldades encontradas e dos desafios colocados. Essa última necessidade ganha destaque na fala a seguir:

Bom... eu quero que eles [a família]... insistam, sabe... com a gente mesmo... com os professores... porque por mais que a gente tente até em algum momento em desistir né... pensa assim: “Ah, eles não vão aprender nada, vamos deixar ele ficar do jeito que quiser... do jeito que dê pra gente levar”. Às vezes a gente pensa realmente isso... porque é muito difícil, mas eu... eles... por parte deles... por parte da família, a insistência... com esse processo de inclusão... Se todos fossem sabedores de seus direitos, ... seria muito bom porque os professores necessitam também de um incentivo emocional também, sabe... psicológico também. (Ent. D, p. 4 , ls. $151-159)$

Tais sentimentos de crise podem ser relacionados às qualidades que os entrevistados atribuem a si mesmos como professores que lidam com a inclusão. Descrevem-se com quatro atributos principais: reforçador, inventivo, atento, despreparado. A qualidade de reforçador expressa-se no cuidado em usar frases 
de incentivo e reforço diante dos trabalhos realizados pelos alunos com deficiência. A inventividade é descrita quando o professor, tendo dificuldade na comunicação com os alunos, tem de inventar novas formas de comunicação. Associado a essas qualidades está o despreparo para dar atendimento adequado; a busca de compensar esse despreparo redunda numa maior atenção aos alunos com deficiência, buscando dar-lhes um atendimento diferenciado. Surge aqui uma questão importante: entendendo a diferenciação como característica apenas da pessoa com deficiência, o professor pode, no esforço de dedicar-se mais a esses alunos, dar um tratamento cada vez mais homogêneo aos demais. Isso explicaria, por exemplo, situações em que o aluno com deficiência se torna exemplo de comportamento disciplinado:

\footnotetext{
São os outros que perturbam... os alunos da educação especial, eles são a maioria deles são comportados... tem alguns que são danados, sabe, mas a maioria deles... noventa por cento deles... você quase nem ouve a voz deles... eles sentam lá, fazem o dever, eles tentam fazer você ensinar, mas os danadinhos são os que não são da educação especial. (Ent. F, p. 6, ls. 295-299)
}

Ao descrever o processo de aprendizagem em que estão envolvidos na experiência da inclusão, aparecem nas falas dos professores três categorias de aprendizado: o aprendizado técnico (no qual eles se envolvem no estudo e treinamento de Libras, Braille, orientação e mobilidade e outras, específicas para cada situação de deficiência); o aprendizado humano, por meio do qual são refinadas a sensibilidade e as emoções, são estabelecidas amizades no processo do mútuo aprender; e o aprendizado pedagógico, já que são necessários novos métodos a cada novo desafio, assim como a experimentação conjunta (professor de turma, alunos e professor de apoio) de novas atividades e técnicas. Esses três tipos de aprendizado são traduzidos geralmente em crescimento pessoal e profissional:

Eu tenho crescido... profissionalmente, eu aprendi que ser diferente é ser normal (risos), que isso aí, né, eu aprendi a conviver com eles de uma forma... Não somente aqui no colégio; tá servindo pra mim lá fora ... que às vezes a gente vê uma pessoa com deficiência e a gente já começa ter um ar assim de "meu Deus, porque aquilo e tal e... são coitadinhos e...” Eles me ensinaram que não existe isso com eles, ... são pessoas que vão atrás mesmo... Então eu cresci. Na verdade é isso... houve crescimento profissional... Eu não sei até quando eu vou continuar com eles, sabe... mas eu tenho uma experiência muito boa mesmo. (Ent. I, p. 5. ls. 207-216)

Diz Oliveira (2007, p. 216), enfatizando o crescimento pessoal e social envolvido na tarefa da inclusão: "A convivência direta, seja familiar ou profissional, com as pessoas que apresentam necessidades educacionais especiais aguça a sensibilidade, a percepção, a compreensão e o interesse por sua situação de excluído social”.

Por fim, o professor de sala regular descreve geralmente a própria postura profissional nos enfrentamentos criados no trabalho pedagógico pela situação de inclusão como proativa. A tomada de iniciativa para melhorar as condições de aprendizagem é a principal temática quando se fala da postura profissional. Em poucos momentos aparece nas falas alguma dependência do pessoal especializado. Nessa tomada de iniciativa, ainda é muito valorizado o atendimento individualizado, tido como essencial na relação com o aluno com deficiência. Como isso é considerado impossível em salas superlotadas, a ação inclusiva acaba aparecendo, contraditoriamente, como inviável. Percebe-se, no modo de operar discursivo, um mecanismo que justifica antecipadamente possíveis fracassos: esse aluno tem de ser atendido individualmente; ou se atende a ele ou se atende aos demais; portanto, há que se fracassar numa das duas possibilidades.

No outro extremo, surgem timidamente iniciativas de trabalho coletivo nas quais o professor passa a dividir com os alunos a responsabilidade pela condução da aprendizagem, como nas falas a seguir:

Eu tento... no máximo incluir eles nessas brincadeiras, tudo... Tem dificuldade de andar, eu boto pra ser juiz... Tem 
dificuldade pra falar, eu boto pra ser outra coisa... Você tem que aproveitar o máximo,... porque até mesmo os próprios meninos excluem eles... Ah, porque ele num sabe, tio, ele num sabe correr. (Ent. C, p. 2, ls. 58-63)

É isso... eu tento essas duas alunas daqui da sala da turma do quinto ano... Eu tento sempre inserir elas em grupos de outras crianças, pra que eles ajudem elas nas atividades, as duas... [...] a E., que é meu outro caso da manhã,[...] ela é Down... eu tou sempre colocando atividades que chamem a atenção dela. Ela gosta muito de pintar... de rabiscar... então eu coloco atividades pra ela, não, eu dou sempre atividades diferenciadas pra ela, não coloco as mesmas atividades que outros alunos... Agora essas duas da tarde não... elas fazem as mesmas atividades que os outros... só que eu sempre tou inserindo elas em grupos de outros alunos pra que eles tejam ajudando elas. (Ent. D, p. 2, ls. 71-80)

Pode-se estabelecer algumas relações, resumindo o lugar de onde o falante se coloca no que se refere à inclusão, tanto nas qualidades, nos sentimentos, na descrição do aprendido e da postura profissional. No geral, o falante descreve-se como parte do processo inclusivo, mesmo quando relata sentimentos como impotência e frustração, quando se sabe despreparado e carente de formação. Esse "sentir-se parte" do processo aparece ainda bastante passivo com relação aos enfrentamentos das carências da educação como um todo, tem mais relação com aquilo que o professor entende que lhe compete: o trabalho de sala de aula, que implica criar melhores condições de aprendizagem para os alunos. Ao contrário do professor de atendimento especializado que, em Anjos (2006), se descreve como um militante da inclusão, o professor de sala comum não toma para si essa tarefa, mas dispõe-se a aprender no fazer pedagógico. A compreensão de que só é possível ensinar à pessoa com deficiência de forma individual e a naturalização das condições de trabalho podem ser fatores limitadores de tal aprendizado. Já a crise evidenciada pode levar a elaborações que criem trajetórias de sucesso em sala de aula, projetando a inclusão para além desse espaço.

\section{Os outros presentes nas falas e seu lugar nos enfrentamentos discursivos}

Partindo do princípio de que todo discurso é dirigido, endereçado (Verón, 1980, p. 77; Bakhtin, 2004, p. 112), de que todo texto responde em alguma medida a outros textos, buscamos localizar como marcas textuais os "outros” sujeitos citados nas falas, e a partir daí analisar em que lugar o falante situa esse “outro”. Alguns “outros” ganham maior evidência, são mais citados, no discurso. O modo de fazer isso traz elementos para elencar e compreender os embates que aparecem como centrais no processo analisado.

Os “outros" que aparecem nas falas dos professores são: o governo, o sistema escolar, os alunos, os pais e o pessoal do atendimento especializado. A figura do governo aparece como um outro geralmente externo, que é responsável pela formação, pela aquisição de materiais para suprir a necessidade dos alunos inclusos e pela conscientização, com ações e propaganda através da mídia. Pouco aparece a noção de que o professor, sendo servidor público, também representa a ação governamental. Além disso, também aparece pouco a noção de inclusão como um projeto de governo, como uma política pública (Oliveira \& Andrade, 2007). O governo aparece no discurso como uma entidade que tem tarefas a cumprir na inclusão, geralmente de incentivo e apoio:

Porque a escola, ela já faz parte do programa do governo, isso... eu acredito que é nessa de articular os pais... e trabalhar também a própria sociedade, não é, isso... porque a mídia, ela tem esses atrativos, isso... mas é muito importante os programas do governo, tá... até mesmo ele tá incentivando, né, o trabalho nessa área... e tá dando apoio maior, né, na... igualmente... porque até esse momento nem era notícia assim... porque o governo, nos últimos anos, eles têm dado realmente apoio... (Ent. B, p. 4, ls. 171-178)

O sistema escolar também é visto como um outro externo ao falante, o qual aparece com algumas especificidades: por um lado, exige, obriga a presença do aluno com deficiência na sala regular; por outro, não 
propicia tempo específico para que o professor atenda a esse aluno, considerando que as turmas continuam superlotadas. São atribuídas ao sistema, ainda, a falta de estrutura física adequada e a falta de material para atender aos alunos, mas não aparece, nas falas dos professores, uma postura de enfrentamento da situação. Por fim, a separação entre pessoal de apoio e do pessoal regular também aparece como própria do sistema, mas não é entendida como desfavorável ao fazer pedagógico.

Aparecem duas categorias na descrição do "outro-aluno". Quando o aluno deficiente aparece em interação com o outro (não-deficiente), este último é descrito como disposto a ajudar, interagindo de forma agradável e cooperativa, compreensivo com relação ao problema do outro (ainda que esse problema continue sendo entendido como “do outro”). Essa relação é descrita como ainda melhor quando o aluno é menor, fazendo supor uma crença de que, crescendo, o aluno tende a tornar-se mais preconceituoso: "Porque eu acho que no meio das crianças assim eles não têm ainda esse pensamento... na minha opinião teria mais discriminação se fosse em adulto” (Ent. F, p. 7, ls. 312314). Quando o aluno deficiente aparece em interação com o professor, é entendido como tendo potenciais para além da deficiência ou para além daquilo que o rótulo de deficiente fazia supor, como diz Rodrigues (2007).

Quase todas as interações descritas dizem respeito a brincadeiras e atividades livres; apenas em um dos trechos de entrevistas essa interação aparece no interior de uma atividade de sala de aula. Percebe-se um reforço da ideia de socialização como indicativo de normalidade (o aluno é tanto mais normal quanto mais interage, diverte-se no grupo), mas essa noção de socialização está mais vinculada a relações sociais de entretenimento do que de ensino-aprendizagem.

Eles sempre brincam com eles, fazem amizades... Eles fazem é gostar de conversar com a $\mathrm{R}$, que é surda-muda eles acham é bom... porque ela fala rápido a língua de sinais e eles inventam e começam a brincar com ela. E ela acha bom, ela gosta de sorrir, aí eles ficam brincando normalmente...
Eles aceitam bem legal, sem discriminação... (Ent. F, p. 6 e 7, ls. 304-309)

Assim, a construção de mecanismos de comunicação, o aprendizado acadêmico e o uso social da leitura e da escrita (Lacerda, 2006) podem acabar sendo colocados em segundo plano, em função de uma socialização restrita e superficial.

As expectativas com relação ao desenvolvimento e à aprendizagem dos alunos diferenciam-se muito conforme o tipo de deficiência. No caso desta pesquisa, foram entrevistados professores que atuam com alunos surdos, cegos, com deficiência mental e Síndrome de Down. Nas expectativas dos professores de alunos com deficiência auditiva e visual percebe-se uma crença maior nas possibilidades de aprendizagem e avanço. Tais professores veem certas qualidades em seus alunos, o que se relaciona com sua expectativa de aprendizagem. Esperam deles, portanto: esforço, força de vontade, desejo de superação, determinação; interação, bom entrosamento com a turma, participação; processos de compensação; independência, comportamento crítico, questionador; busca de superação da baixa expectativa social. Quando os falantes atuam com alunos com Síndrome de Down e deficiência mental em geral, aparecem outras expectativas, mais relacionadas a pouco rendimento e lentidão na realização das tarefas. Em ambos, aparecem elementos contraditórios. Espera-se obediência e disciplina como características positivas do aluno com deficiência, em contraposição à rebeldia descrita no aluno tido como normal; acompanhamento dos conteúdos como demonstração de normalidade (os alunos com deficiência visual e auditiva são descritos como bons porque, quando se estabelece com eles mecanismos de comunicação e linguagem, são inteligentes, acompanham os conteúdos trabalhados; os alunos com deficiência mental são vistos como mais afastados da normalidade porque não podem fazer isso). $\mathrm{O}$ domínio dos conteúdos e das competências escolares acaba emergindo como condição para a superação do preconceito. Percebe-se, portanto, que o foco continua no aluno e em suas competências e incompetências, 
e não no coletivo (Silva, 2006), assim como continua vigente um desejo de padronização (Rodrigues, 2007).

Nas análises das entrevistas percebe-se que os pais aparecem nos dois extremos: tanto como um "outro" que tem envolvimento e participação na vida escolar do aluno quanto como um “outro” distanciado, que não dá o apoio necessário ou que não tem condições financeiras para propiciar o atendimento complementar de que uma criança deficiente precisa. Mesmo nos casos em que é descrita participação da família (em que se percebe cobrança com relação à aprendizagem do filho), esta é avaliada como desinformada, sem a compreensão do processo de aprendizagem do aluno, havendo, dessa maneira, dificuldade de avaliar seus avanços. Nas falas, os pais aparecem também como super-protetores, com uma ação contrária à da escola, que busca desenvolver a autonomia do aluno. Entendidos como membros de um grupo diferente, com sua própria complexidade, os pais são vistos como externos ao processo educativo que ocorre na escola.

A expectativa mais evidente com relação ao trabalho do professor que cuida do AEE, que atende nas salas de atendimento especializado, nas salas multifuncionais ou como professor itinerante, ${ }^{5}$ é que ele trate apenas das questões referentes à educação dos alunos com deficiência. Não aparece nenhuma expectativa de que esse profissional possa contatar os alunos tidos como normais para discutir inclusão, de que tenha opiniões e informações acerca da educação em geral.

Todas as outras expectativas têm relação com essa primeira, já que tratam geralmente de tarefas específicas do que se denominou educação especial (uma educação separada, mesmo quando junta). Nesse sentido, inclusão é tida como sinônimo de educação especial (Mendes, 2006) e é entendida como tarefa do profissional de AEE. A expectativa, por exemplo, é de que esse profissional adapte e prepare material para os alunos, considerando que seu material é es-

${ }^{4}$ As salas de recursos atendem a alunos com limitações específicas; as salas multifuncionais, a alunos com limitações diversas, de forma conjunta; o professor itinerante acompanha a atividade docente e discente nas escolas. pecífico (em Braille ou ampliado, para os alunos com deficiência visual). Supõe-se também que cabe ao professor especializado mediar a relação emocional e cognitiva entre os alunos com deficiência e o professor, reduzindo os conflitos. Interessante, nesse caso, é que alguns dos conflitos citados têm a ver com indisciplina (o aluno não querer fazer a tarefa ou não demonstrar respeito pelo professor) e não necessariamente com a deficiência. De qualquer forma, espera-se que o professor especializado seja responsável também por esses aspectos, já que se trata do aluno “dele”.

O conteúdo dela é específico, acho até mesmo na parte de, de... de desenvolvimento... da própria aluna... Eu acredito que seja... é que eu nunca me informei com ela qual a área que ela trabalha especificamente,... porque a gente na sala de aula normal a gente tem todas as disciplinas... [...] Aqui a gente tem a [facilidade] de a gente ter o apoio da S. Ela gosta muito de trabalhar nessa área, ... ela tem vários alunos, tá... Muito boa essa menina... ela tem vários alunos. (Ent. B, p. 3-4, ls. 143-147 e 189-192)

Assim, o professor de AEE deve trazer informações específicas acerca da deficiência, fornecer treinamento técnico (Braille, Libras, Soroban), preparar os alunos com deficiência para estar na sala comum, adaptando-se a ela e não o contrário (numa perspectiva claramente integracionista). O não-dito, mas evidente, é que há expectativa de que tal acompanhamento não interfira na ação dada como própria do professor de sala comum: aquela que se refere aos alunos "sem deficiência". Espera-se que assessore "de fora", sem se relacionar com as questões gerais da sala de aula.

A rede de relações discursivas que aparece quando o falante dialoga com esses interlocutores, que lhe parece importante no processo de inclusão, mostra distinção clara entre o mundo onde o professor tem uma função de direção (a sala de aula) e o resto do mundo. Governo, sistema escolar, pais, alunos, pessoal de atendimento especializado são temáticas que têm relações com esse fragmento de mundo, mas tais relações não aparecem, no modo de operar discursivo, como interconstitutivas. Quer dizer, ainda que seja um 
servidor público (portanto, sua presença em sala de aula é, de algum modo, a presença do governo), ainda que seja um professor (portanto, inserido no sistema escolar), seu modo de descrever essas duas instâncias mostra distanciamento, afastamento de si.

A descrição da superlotação das salas, da falta de debate prévio acerca da distribuição dos alunos nas turmas, as críticas ao processo de formação, enfim, todos os fatores apontados como desfavoráveis ao processo de inclusão aparecem naturalizados no discurso, ou pelo menos fora do alcance da ação do professor. Com relação aos pais, também se configuram num mundo à parte, mesmo quando contribuindo e se interessando. Os profissionais de atendimento especializado são entendidos como aqueles que devem ocupar-se do aluno deficiente, ajudar a reduzir os conflitos criados por sua presença na sala de aula, mas que não mudam a dinâmica central do fazer pedagógico, voltado para a normalidade ou para a normalização (Crochik, 2007). E, de forma complementar a esse modo de operar, a descrição desses alunos esboça-os como um "outro" interessante na medida em que se enquadram nas exigências curriculares padronizadas (cabem no mundo escolar): mostram-se inteligentes, dominam o conteúdo, são dóceis. A presença da diferença em classe, nesses casos, não ameaça o status quo. Pelo contrário, cria exemplos de comportamento para os indóceis ou apáticos “normais”. De qualquer modo, tais alunos continuam sendo descritos como “da educação especial”, apesar de estarem na classe comum. O rótulo não os abandona (Silva, 2006); eles continuam sendo de um outro território.

\section{A título de conclusão}

Os enfrentamentos e diálogos presentes nas falas dos professores mostram que, no movimento de constituição do discurso pedagógico acerca da inclusão, algumas organizações discursivas se mostram dominantes, enquanto outras aparecem em embate, disputando posições nas falas dos professores.

Pode-se destacar como tendências dominantes no discurso: a tendência a recortar os territórios relativos à inclusão, estabelecendo os limites da sala de aula como território do professor e remetendo ao atendimento especializado a responsabilidade para com o aluno com deficiência; a tendência a estabelecer como parâmetro de sucesso a adequação aos espaços escolares tal como eles se mostram; a noção de externalidade das instâncias decisórias e propositivas, tais como governo e sistema educacional.

Os principais embates evidenciados no discurso são: o enfrentamento entre inclusão entendida como processo ou como produto, embate que, no limite, definirá a maior ou menor participação e intervenção dos professores nos processos inclusivos; os sentimentos caracterizados como de crise, os quais podem levar a elaborações que modifiquem o fazer pedagógico e o projetem para além do espaço escolar.

Certas contradições, ainda que não se configurem propriamente em enfrentamento neste momento histórico, também devem ser evidenciadas, por seu potencial crítico. Por exemplo, ao precisar trabalhar com um aluno que, ao mesmo tempo, é e não é de sua responsabilidade, o professor precisará equacionar tal contradição, e uma das perspectivas é de que se intensifiquem as trocas com o pessoal de atendimento educacional especializado. Este, acompanhando o trabalho pedagógico, não deixará de saber e dar sugestões para o trabalho do outro, ampliando-se as possibilidades de ação coletiva.

Pode-se afirmar que a distinção anteriormente descrita, separando o mundo pedagógico e o resto das relações, reforça aquela concepção de inclusão como produto e não como processo, analisada no primeiro agrupamento de sentidos. Esse reforço dá-se porque, separando o seu fazer do fazer coletivo, o professor passa a entender a inclusão como tarefa somente sua, circunscrita aos limites do pedagógico e imposta a partir de forças externas. Assim, a produção de processos excludentes não é enfrentada, e o processo inclusivo limitado à sala de aula ou, na melhor das hipóteses, à escola está fadado ao fracasso. Recortar o processo inclusivo que ocorre no interior da sala de aula, separando-o das discussões mais gerais da inclusão/exclusão, é um movimento que impede sua 
expansão e reduz seu poder mobilizador.

Incluir, nessa concepção, reduz-se a trazer para dentro da escola os alunos deficientes, buscando criar condições de atendimento às necessidades educacionais criadas com tal inserção, sem questionar o processo de produção social da deficiência (Diniz, 2007). Não se situa a exclusão no interior dos processos pedagógicos; ela é entendida como própria do sistema, e este entendido como externo ao fazer pedagógico. Dedicado a criar melhores condições de aprendizagem para os alunos, o professor pode atribuir a si mesmo (e ao próprio despreparo) e ao aluno (e à deficiência que lhe é integralmente atribuída) certos fracassos, deixando de perceber suas relações com mecanismos estruturais de exclusão. Para que ocorram de fato processos inclusivos, é necessário detectar e enfrentar os processos excludentes, dos quais o professor é vítima e também pode ser promotor, se não se der conta disso.

\section{Referências bibliográficas}

ANJOS, Hildete Pereira dos. O espelho em cacos: análise dos discursos imbricados na questão da inclusão. Tese (Doutorado em Educação) - Faculdade de Educação, Universidade Federal da Bahia, 2006.

BAKHTIN, Mikhail. M. Marxismo e filosofia da linguagem. 11. ed. Trad. Michel Lahud e Yara Frateschi Vieira. São Paulo: Hucitec, 2004.

Estética da criação verbal. 4. ed. Trad. Paulo Bezerra. São Paulo: Martins Fontes, 2003.

BRASIL. Conselho Nacional de Educação. Resolução CNE/CEB n. 02, de 11 de fevereiro de 2001. Disponível em: <http://www. mec.gov.br/seesp>. Acesso em: 5 fev. 2007.

CARTOLANO, Maria Teresa Penteado. Formação do educador no curso de pedagogia: a educação especial. Cadernos CEDES, n. 46, p. 29-40, 1998.

CROCHIK, Leon. Normalização e diferenciação do indivíduo com deficiência mental. Revista da FAEEBA: Educação e Contemporaneidade, v. 16, n. 27, p. 19-29, 2007.

DINIZ, Débora. O que é deficiência. São Paulo: Brasiliense, 2007. FOUCAULT, Michel. A ordem do discurso. 13. ed. Trad. Laura Fraga de Almeida Sampaio. São Paulo: Loyola, 2006.
LACERDA, Cristina Broglia Feitosa de. A inclusão escolar de alunos surdos: o que dizem alunos, professores e intérpretes sobre esta experiência. Cadernos CEDES, v. 26, n. 69, p. 163-184, 2006. LIBÂNEO, José Carlos. As teorias pedagógicas modernas revisitadas pelo debate contemporâneo da educação. In: LIBÂNEO, José Carlos; SANTOS, Akiko (Orgs.). Educação na era do conhecimento em rede e transdisciplinaridade. Campinas: Alínea, 2005. p. 19-62. MARABÁ. Relatório referente aos meses de março, abril e maio. Secretaria Municipal de Educação, Setor de Educação Especial, 2001. Mimeografado.

MARCHESI, Álvaro; MARTIN, Elena. Da terminologia do distúrbio às necessidades educacionais especiais. In: COLL, César S.; PALÁCIOS, Jesus; MARCHESI, Álvaro. Desenvolvimento psicológico e educação: necessidades educativas especiais e educação. Trad. Marcos A. G. Domingues. Porto Alegre: Artes Médicas, 1996. p. 7-23.

MENDES, Enicéia Gonçalves. A radicalização do debate sobre inclusão escolar no Brasil. Revista Brasileira de Educação, v. 11, n. 33, p. 387-405, 2006.

OLIVEIRA, Ivanilde Apoluceno de. Educação inclusiva e formação de professores: a importância do corporal sensível. In: PIZZI, Laura C. Vieira; FUMES, Neiza Frederico. Formação do pesquisador em educação: diversidade, inclusão e juventude. Maceió: EDUFAL, 2007. p. 213-227.

OLIVEIRA, Maria Vieira M. de; ANDRADE, Francisca R. Bezerra. Políticas públicas para a educação especial: uma análise teórico-documental (1994-2002). In: ENCONTRO DE PESQUISA EM EDUCAÇÃO DO NORTE E NORDESTE, 18., 2007, Maceió. Anais... Maceió: UFAL, 2007. 1 CD-ROM.

OMOTE, Sadao. Inclusão: intenção e realidade. Marília: FUNDEPE, 2004.

ORLANDI, Eni Pulcinelli. Análise de discurso: princípios e procedimentos. 5. ed. Campinas: Pontes, 2005.

PÊCHEUX, Michel. O discurso: estrutura ou acontecimento. 4. ed. Trad. Eni P. Orlandi. Campinas: Pontes, 2006.

RODRIGUES, Graciela Fagundes. A inclusão e suas relações no cotidiano escolar. Revista da FAEEBA: Educação e Contemporaneidade, v. 16, n. 27, p. 97-104, 2007.

SILVA, Luciene Maria da. O estranhamento causado pela deficiência: preconceito e experiência. Revista Brasileira de Educação, v. 11, n. 33, p. 424-434, 2006.

SKLIAR, Carlos. Perspectivas políticas e pedagógicas da educação bilíngüe para surdos. In: SILVA, Shirley; VIZIM, Marli (Orgs). 
A inclusão escolar do ponto de vista dos professores: o processo de constituição de um discurso

Educação especial: múltiplas leituras e significados. Campinas: Mercado das Letras/Associação de Leitura do Brasil, 2001. p. 85-109. VERÓN, Eliseo. Fragmentos de um tecido. Trad. Vanise Dresch. São Leopoldo: Editora Unisinos, 2004.

. A produção de sentido. Trad. Alceu Dias Lima et al. São Paulo: Cultrix/EDUSP, 1980.

VYGOTSKY, Lev S. Fundamentos de defectología. Obras completas, tomo V. Ciudad de la Habana: Editorial Pueblo y Educación, 1989.

. Teoria e método em psicologia. Trad. Cláudia Berliner. São Paulo: Martins Fontes, 1996.

. A formação social da mente. Trad. José Cipolla Neto, Luiz Silveira Menna Barreto e Solange Castro Afeche. São Paulo: Martins Fontes, 1998.

. A construção do pensamento e da linguagem. Trad.

Paulo Bezerra. São Paulo: Martins Fontes, 2000.

HILDETE PEREIRA DOS ANJOS, doutora em educação pela Universidade Federal da Bahia (UFBA), é professora adjunta da Universidade Federal do Pará (UFPA), campus de Marabá, e coordenadora do Grupo de Estudos e Pesquisas do Núcleo de Educação Especial (GEP/NEES). Publicações recentes: “O espelho em cacos: análise dos discursos imbricados na questão da inclusão" (In: ENCONTRO DE PESQUISA EM EDUCAÇÃO DO NORTE E NORDESTE, 18., 2007, Maceió. Anais... Maceió: UFAL, 2007. 1 CD-ROM); com CAVALCANTE, L. C.; LIRA, F. M.; ARAÚJO, M. A.; BEZERRA, W. L. “Zonas de sentido no discurso pedagógico: professor, aluno e ação educativa” (In: REUNIÃO ANUAL DA SBPC, 59., 2007, Belém. Anais... Belém: SBPC, 2007); "Discutindo concepções sobre inclusão e seu impacto na prática inclusiva” (In: CONGRESSO BRASILEIRO DE EDUCAÇÃO ESPECIAL, 2., 2005, São Carlos. Livro de Programas e Resumos do II Congresso Brasileiro de Educação Especial. São Carlos: UFSCAR, 2005. p. 259-259); "Da infância e do presente"
(A Con Te Cer - Jornal da Pós-Graduação em Educação da Faced UFBA, v. 1, p. 4-5, 2004). Pesquisas em desenvolvimento: "Educação Inclusiva em municípios do Pará - o caso de Marabá”, parte do programa de pesquisa "Olhar, escutar e vivenciar a educação inclusiva em municípios do Pará”, da Rede de Pesquisa em Educação Inclusiva na Amazônia Paraense, financiado pelo Conselho Nacional de Desenvolvimento Científico e Tecnológico (CNPq); “A experiência de inclusão dos alunos com necessidades especiais nas escolas públicas de Marabá: primeiras avaliações”, financiado pelo Programa de Auxílio à Instalação do Professor Recém-Doutor (PARD), da UFPA.E-mail: hpanjoma@ufpa.br

EMMANUELE PEREIRA DE ANDRADE, graduanda em pedagogia pela Universidade Federal do Pará (UFPA), é membro do Grupo de Estudos e Pesquisas do Núcleo de Educação Especial (GEP/NEES) e bolsista do projeto “A experiência de inclusão dos alunos com necessidades especiais nas escolas públicas de Marabá: primeiras avaliações”, coordenado pela professora Hildete Pereira dos Anjos e financiado pelo Programa de Auxílio à Instalação do Professor Recém-Doutor (PARD), da UFPA. E-mail: manuxinhaufpa@hotmail.com

MIRIAN ROSA PEREIRA, graduanda em pedagogia pela Universidade Federal do Pará (UFPA), é membro do Grupo de Estudos e Pesquisas do Núcleo de Educação Especial (GEP/NEES). Foi bolsista, durante o ano de 2007, do projeto “A experiência de inclusão dos alunos com necessidades especiais nas escolas públicas de Marabá: primeiras avaliações”, coordenado pela professora Hildete Pereira dos Anjos e financiado pelo Programa de Auxílio à Instalação do Professor Recém-Doutor (PARD), da UFPA. E-mail: mirian-pereira@hotmail.com

Recebido em junho de 2008 Aprovado em setembro de 2008 